\title{
Erratum to: The time course of auditory and language-specific mechanisms in compensation for sibilant assimilation
}

\author{
Meghan Clayards $^{1,2} \cdot$ Oliver Niebuhr $^{3} \cdot$ M. Gareth Gaskell ${ }^{4}$
}

Published online: 9 November 2015

(C) The Psychonomic Society, Inc. 2015

Erratum to: Attention, Perception, \& Psychophysics, 77(1), 311-328.

DOI 10.3758/s13414-014-0750-z

Due to an error during the production stage, the same graph was used for Fig. 5 on page 321 and Fig. 3 on page 320 . Figure 3 in the original article was correct, but Fig. 5 was incorrect. The corrected Fig. 5 appears below.

The online version of the original article can be found at http://dx.doi.org/ 10.3758/s13414-014-0750-z.

Meghan Clayards

meghan.clayards@mcgill.ca

1 Department of Linguistics, McGill University, Montreal, Quebec, Canada

2 School of Communication Sciences and Disorders, McGill University, Montreal, Quebec, Canada

3 Department of General and Comparative Linguistics, University of Kiel, Kiel, Germany

4 Department of Psychology, University of York, York, UK 


\section{English group}

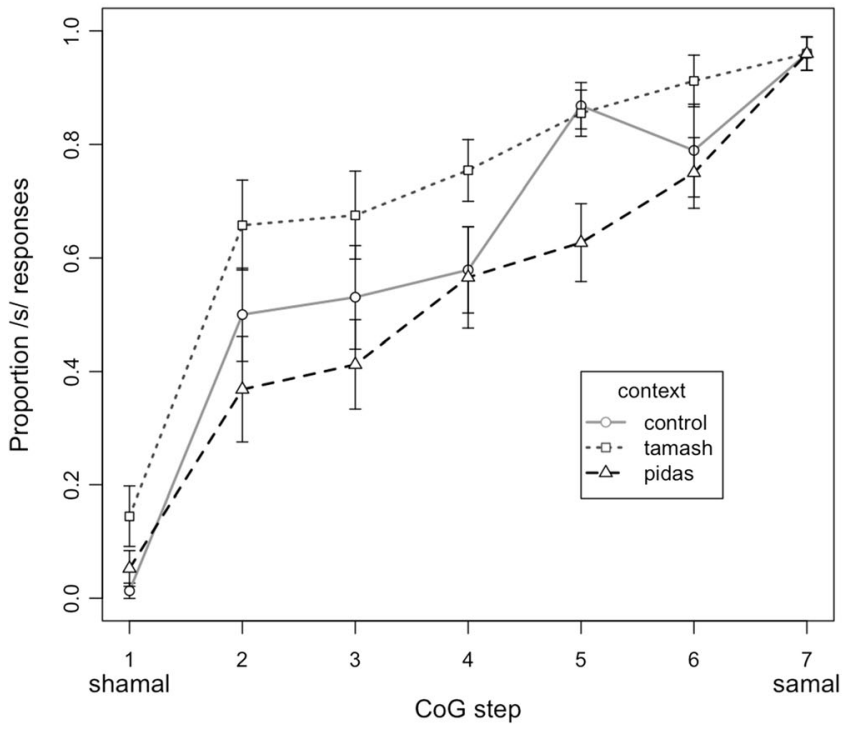

Fig. 5 Mouse-click responses for the two groups of listeners categorizing the shamal-samal continuum after one of three different contexts: control (solid lines, circles), tamash (dotted lines, squares) and pidas (dashed

\section{French group}

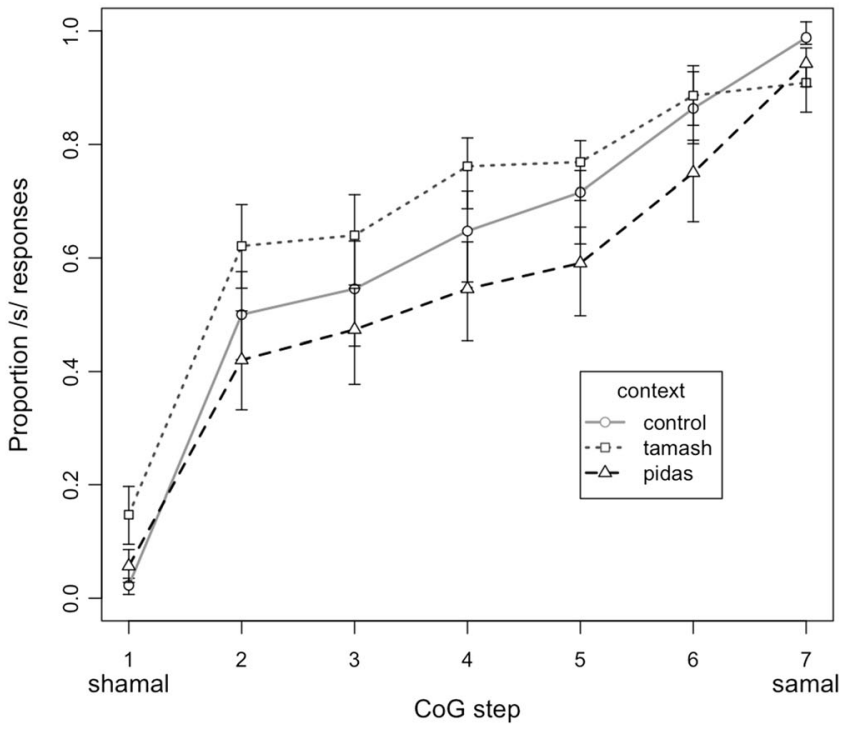

lines, triangles). Error bars are standard errors of the means by subjects and do not reflect the standard error of the model 